\title{
Damping Local Oscillations of a Direct- Drive PMSG Wind Turbine
}

\author{
Ayele N. Legesse ${ }^{\# 1}$, Akshay K. Saha ${ }^{\# 2}$, Rudiren Pillay Carpanen ${ }^{\# 3}$

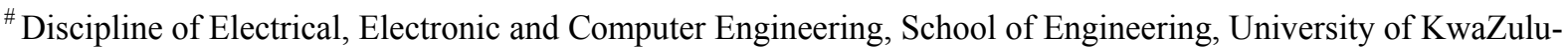 \\ Natal, Durban 4041, South Africa \\ ${ }^{1}$ 214584668@stu.ukzn.ac.za \\ ${ }^{2}$ saha@ukzn.ac.za \\ ${ }^{3}$ PillayR21@ukzn.ac.za
}

\begin{abstract}
Damping local oscillations is vital in the operation of a direct-drive permanent magnet synchronous generator wind turbine as well as its integration into a grid. Currently, these oscillations are controlled by proportional-integral controllers. This paper proposes the inclusion of virtual resistors to improve the performance of the wind turbine further. Simulation results show that virtual resistors, connected in series to stator windings, have a positive impact on the damping of local oscillations. They significantly reduce the rise and settling times of the rotor speed, electromagnetic torque, active power and reactive power and increase the corresponding damping ratios. In contrast, the ones, connected in parallel to stator windings, have a negative impact on the damping of local oscillations. This indicates that an appropriate selection and connection of virtual resistors improves the dynamic and small-signal performances of a PMSG wind turbine.
\end{abstract}

Keyword-Damping local oscillations, permanent magnet synchronous generator, wind turbine, dynamic performance, small-signal stability, virtual resistors

\section{INTRODUCTION}

For the past two centuries, rapidly growing populations and modernization trends have accelerated the demand for energy. Today, the world heavily depends on fossil fuels such as oil, coal, and natural gas for its increasing energy requirements. However, this fossil-fuelled economy is facing challenges including depletion of reserves, global warming, security concerns, and rising cost [1]. In tackling these challenges, much attention is given to the development of renewable energy, among which harnessing wind energy is the cheapest alternative $[2,3]$.

Three types of wind energy technologies- squirrel-cage induction generator (SCIG), doubly fed induction generator (DFIG) and permanent magnet synchronous generator (PMSG) wind turbines- are widely adopted in the wind industry. Compared to SCIG, DFIG and PMSG are popular for two reasons [4]. Firstly, they offer the opportunity to operate the machine at maximum power for various wind speeds, and secondly, they have less mechanical stress on their shafts. These days, the popular variable-speed wind turbines employed in large-scale wind parks are DFIG wind turbines [5]. Nevertheless, recently, direct-drive PMSG wind turbines are gaining momentum among researchers, engineers and turbine manufacturers for their high efficiency, low power loss and smaller size $[6-11]$.

The integration of wind power into grids is rapidly growing. In some European countries, the level of penetration has reached as high as $21 \%$ [12]. However, due to this high penetration and the intermittent nature of the wind, there are concerns such as generation reserve, power system stability and reliability [13]. Furthermore, wind turbines themselves have stability problems, which surely challenge transmission system operators. In large grids, the ability of both local and system-wide power system oscillation damping plays a crucial role [14].

A range of efforts have been made to damp local oscillations of a PMSG wind turbine based on active power control [14 - 21] and reactive power control [4, 21 - 25]. For example, in [16], a mechanical method using springs and dampers is employed to give the PMSG wind turbine a damping capability. On the other hand, [19] investigates an active damping strategy based on DC-link current estimation to damp torsional oscillations. The researchers focus on improving damping of oscillations through the power electronic converters using proportional-integral (PI) controllers [14]. However, the performance of virtual resistors to damp local oscillations in a PMSG wind turbine, particularly from the generator side, has not yet been investigated.

The aim of this paper, therefore, is to investigate the performance of virtual resistors in damping local oscillations of a PMSG wind turbine. As the resistors are virtual resistors, they do not incur power loss. Moreover, they can be connected in either parallel or series to the stator windings and implemented in the generator side converter controller. 
This paper is organized as follows: Section II presents the models of the virtual resistors and the different components of the wind turbine, Section III briefly illustrates the model of the power grid, simulation results are presented and discussed in IV, and finally, in $\mathrm{V}$, a conclusion is drawn, and a future work is recommended.

\section{DynAmic Modeling OF A PMSG Wind TURBINE}

In recent configurations, it is common to see wind turbines employing PMSGs, as shown in Fig. 1. The rotor drives the PMSG without a gear. The generator is connected to the power grid through power electronic converters, a filter, and a transformer, where the power electronic converters convert the low-frequency (10-15 $\mathrm{Hz}$ ) voltage of the generator into a 50 or $60 \mathrm{~Hz}$ voltage. Subsequently, the filter filters the harmonics created by the power electronic converters out while the transformer steps up the output voltage to the grid voltage level $[26-29]$.

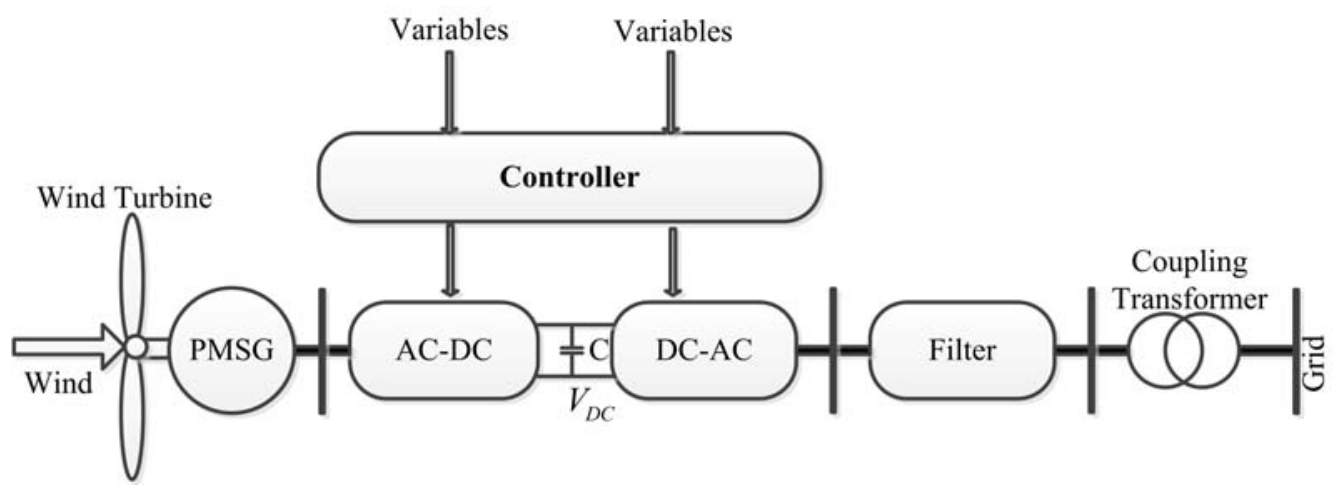

Fig.1. A PMSG wind turbine connected to a grid

The next sub-sections discuss the models of the major components of the PMSG wind turbine.

\section{A. Wind Speed}

Wind speed depends on the climate and geographic location of the wind farm. In nature, the wind is a random variable, consisting of components such as base speed, gust, ramps and background noise [5]. In this study, the model in (1), a Fourier series representation, is considered to represent such behaviours of the wind.

$$
v_{w}(t)=v_{0}+\sum_{k=1}^{N} a_{k} \sin \left(\omega_{k} t\right)+\sum_{k=1}^{N} b_{k} \cos \left(\omega_{k} t\right)
$$

$v_{w}$ is the wind speed, $v_{0}$ refers to the base component of the wind speed, $a_{k}$ and $b_{k}$ are sine and cosine coefficients respectively, $\omega_{k}$ is the angular frequency of the kth harmonics, and $N$ is the number of harmonics. Appropriate selection of the harmonics can approximate the gust, ramp and background noise components of the wind speed. Particularly, the harmonics are used to study the small-signal stability of the PMSG wind turbine, related to wind speed disturbances in section IV.

\section{B. Drive Train}

The power electronic converters in Fig. 1 decouple the wind turbine from the grid. Thus, the transients in the grid could not be seen in the PMSG wind turbine [30], and the drive train is modeled using a one mass model as shown in (2).

$$
\begin{aligned}
\frac{d \omega_{m}}{d t} & =\frac{1}{J}\left(T_{m}-T_{e}\right) \\
J & =J_{t}+J_{g}
\end{aligned}
$$

$J$ is the moment of inertia of the whole drive train, $J_{t}$ is the moment of inertia of the wind turbine, and $J_{\mathrm{g}}$ is the moment of inertia of the generator. $\omega_{m}$ is the rotor speed, and $T_{m}$ is the mechanical torque which is given as,

$$
T_{m}=\frac{P_{w}}{\omega_{m}}
$$

The wind power, $P_{w}$, depends on the density of air, $\rho$, tip to wind speed ratio, $\lambda$, pitch angle, $\theta_{p}$, area swept by the blades, $A_{r}$, and the wind speed.

$$
P_{w}=\frac{1}{2} \rho C_{P}\left(\lambda, \theta_{p}\right) A_{r} v_{w}^{3}
$$


$C_{P}$, which is the power coefficient of the wind turbine, depends on $\lambda$ and $\theta_{p}$. It is usually given as [26],

$$
\begin{gathered}
C_{P}=0.5\left(\frac{116}{\lambda_{i}}-0.4 \theta_{p}-5.0\right) e^{\frac{-21}{\lambda_{i}}} \\
\frac{1}{\lambda_{i}}=\frac{1}{\lambda+0.08 \theta_{p}}-\frac{0.035}{\theta_{p}^{3}+1}
\end{gathered}
$$

\section{Pitch Angle and Speed Controllers}

The pitch angle controller maintains the rated value of the real power of the PMSG for wind speeds, exceeding the nominal value. For speeds less than the nominal value, the pitch angle is zero. In this work, a proportional controller, as shown in (8), is considered. Besides, the controller contains rate, upper and lower limiters.

$$
\theta_{p}=K_{p}\left(\omega_{m}-\omega_{m r e f}\right)
$$

$K_{p}$ is a proportional constant, and $\omega_{\text {mref }}$ is the reference rotor speed.

In (5) and (6), the wind turbine power depends on the wind speed and the pitch angle. For a particular wind speed and pitch angle, there is an optimum rotor speed at which the output power is also optimum. The controller tries to keep the generator at this optimum power. Equation (9) gives the speed controller [31].

$$
P_{\text {ref }}=\left\{\begin{array}{l}
P_{\text {rated }} \text { for } \omega_{m}>\omega_{m \text { nominal }} \\
K_{\text {opt }} \omega_{m}^{3} \text { or } \omega_{m} \leq \omega_{m \text { nomin } a l}
\end{array}\right.
$$

$P_{\text {ref }}$ is the reference wind turbine power, whereas $P_{\text {rated }}$ is the rated output power of the PMSG. $K_{\text {opt }}$ is a constant.

\section{PMSG Model}

In filters, oscillations and harmonics are damped using active damping techniques, which employ virtual resistors not to incur power loss [32]. In this work, the same trend is applied to damp the local oscillations of a PMSG wind turbine.

The virtual resistors, adopted here, are supplementary algorithms [33], and hence, in practice, they are realized in the generator side converter controller. The winding resistance of the generator can slightly damp power and speed oscillations, but it does not have a significant impact on the damping of local oscillations, and thus, the need for virtual resistors.

Fig. 2 shows the d-axis and $q$ - axis equivalent circuits of a PMSG with virtual resistors, connected in series and parallel to the stator windings. In this paper, the parallel connections, shown in Figs. 2(c) and (d), are selected as they do not decrease the effective resistance of the generator.

Applying Kirchhoff's voltage law to the equivalent circuits shown in Fig. 2 (a) and (b), the corresponding new d- axis and q-axis voltages, which are considered as references in the generator side controller, are given in (10) and (11).

$$
\begin{gathered}
v_{d}^{*}=R_{s} i_{d}+L_{d} \frac{d i_{d}}{d t}-\omega L_{q} i_{q}+R_{v} i_{d} \\
v_{q}^{*}=R_{s} i_{q}+L_{q} \frac{d i_{q}}{d t}+\omega\left(L_{d} i_{d}+\phi_{p}\right)+R_{v} i_{q}
\end{gathered}
$$

$R_{s}$ and $R_{v}$ are armature and virtual resistances respectively. $L_{d}$ and $L_{q}$ are $d$ - and $q$-axis inductances, $\omega$ is rotor speed in electrical radian, $i_{d}$ and $i_{q}$ are $d$ - and $q$-axis currents, and $\phi_{p}$ is permanent magnet flux.

Similarly applying the same method to Fig. 2 (c) and (d), we have

$$
v_{d}^{*}=R_{s} i_{d}+L_{d} \frac{d\left(i_{d}+i_{d v}\right)}{d t}-\omega L_{q} i_{q}
$$




$$
v_{q}^{*}=R_{s} i_{q}+L_{q} \frac{d\left(i_{q}+i_{q v}\right)}{d t}+\omega\left(L_{d} i_{d}+\phi_{p}\right)
$$

where $i_{d v}$ and $i_{q v}$ are $d$ - and $q$ - axis virtual currents.

Analysing (10), (11), (12) and (13) gives the block diagrams in Figs. 3(a), (b), (c) and (d) respectively, which are used to analyse the dynamic behaviour of the PMSG. In all the four diagrams, the inner loops represent parts of the generator itself, whereas the outer feedback loops are components that appear due to the virtual resistors.

The electromagnetic torque developed in the PMSG is given as [5],

$$
T_{e}=\frac{3}{4} p\left(\phi_{p} i_{q}+\left(l_{d}-L_{q}\right) i_{d} i_{q}\right.
$$

$p$ is the number of poles of the PMSG.

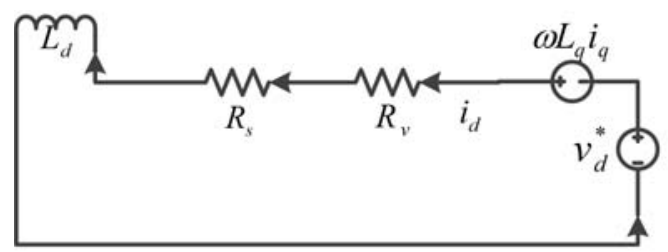

(a)

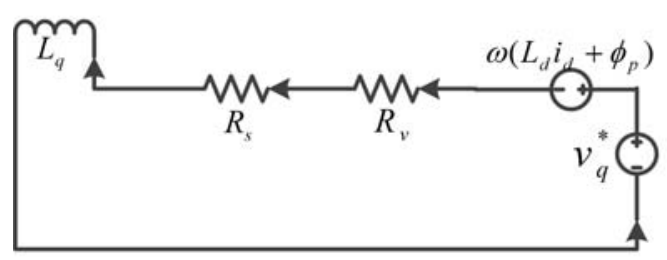

(b)

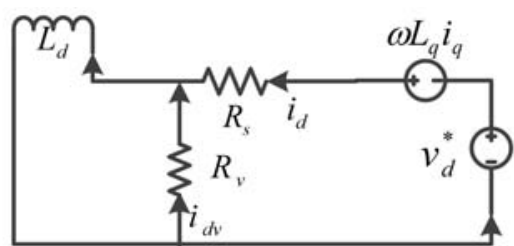

(c)

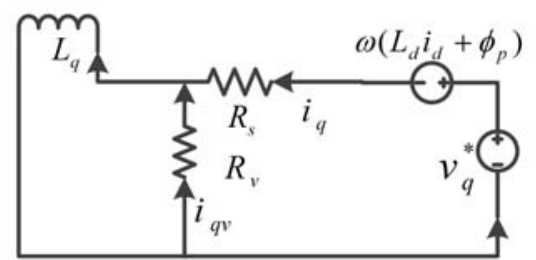

(d)

Fig. 2. Equivalent circuits of a PMSG with virtual resistors (a) d- axis series virtual resistor (b) q-axis series virtual resistor (c) d-axis parallel virtual resistor (d) q- axis parallel virtual resistor

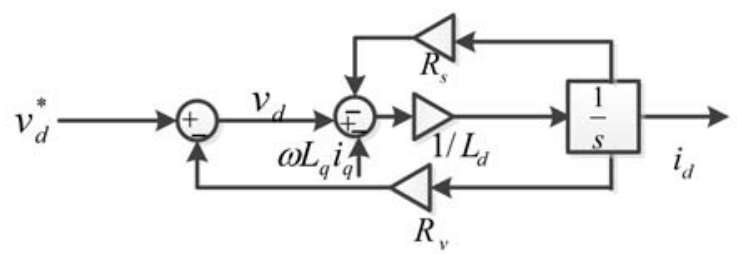

(a)

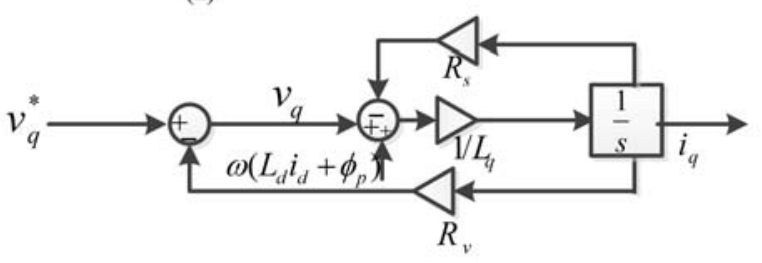

(b)

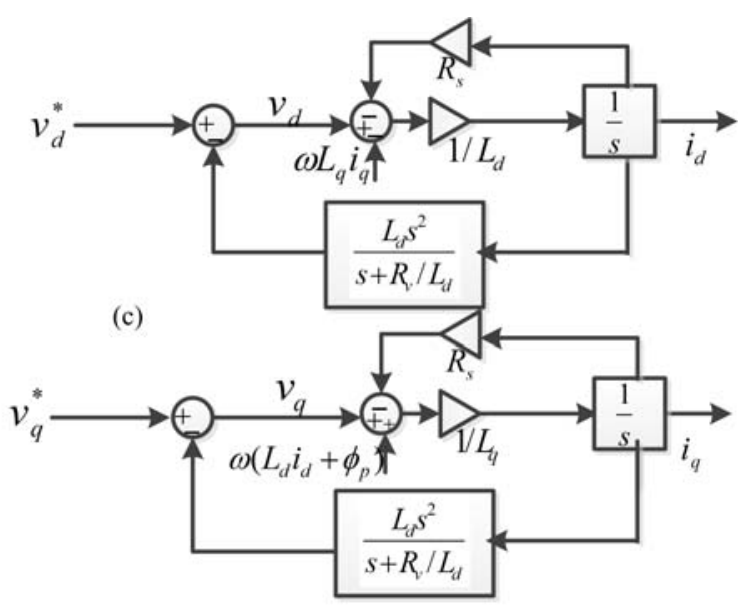

(d)

Fig. 3. Block diagrams of the PMSG equivalent circuits (a) d- axis circuit with series virtual resistance (b) q-axis circuit with series virtual resistance (c) d- axis circuit with parallel virtual resistance (d) q- axis circuit with parallel virtual resistance 


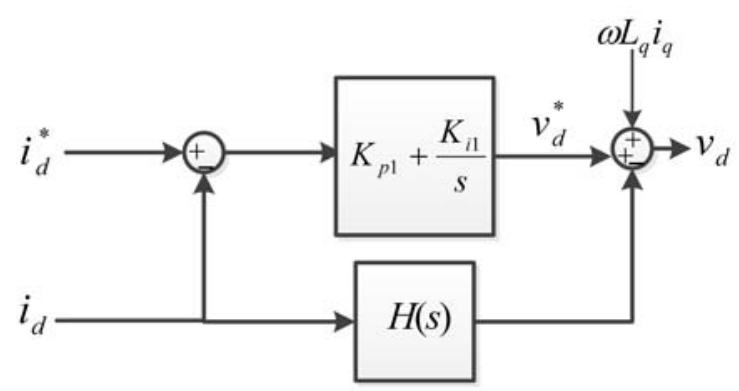

(a)

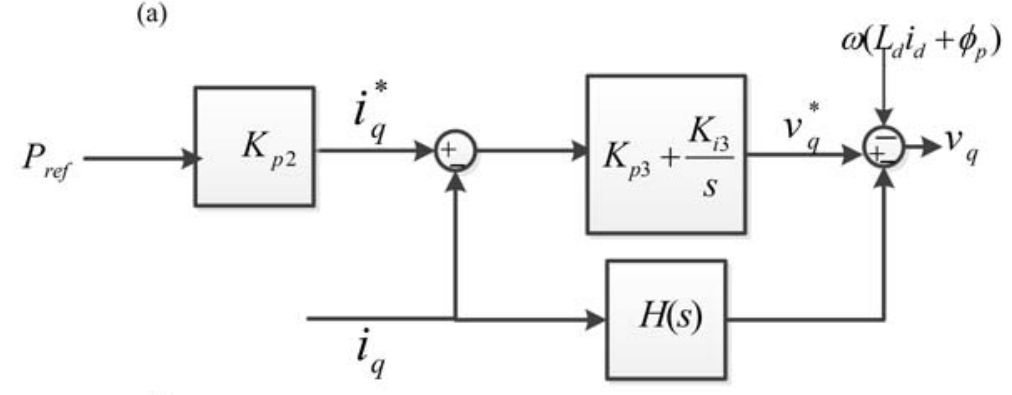

(b)

Fig. 4. Proposed generator side controller (a) $i_{d}$ controller (b) $i_{q}$ controller with virtual resistance scheme

\section{E. Generator Side Converter Controller}

The generator side controller controls the active power of the PMSG through the quadrature axis voltage, $v_{q}$. This scheme aims at minimizing the power loss. On the other hand, the direct axis current is kept at zero to decrease the nonlinearity of (14) and minimize current coupling and is achieved through the direct axis voltage, $v_{d}[31]$.

In this control structure, a proportional and two proportional-integral (PI) controllers are employed, as shown in Fig. 4. The PI controller in Fig. 4(a) controls the d- axis current, whereas the one in Fig. 4(b) controls the qaxis current. $K_{p 1}, K_{p 2}, K_{\mathrm{p} 3}, K_{i 1}$, and $K_{i 3}$ are the gains of the controllers. The superscript * denotes a reference value. The negative forward loop, with a transfer function shown in (15), is the effect of the virtual resistor.

$$
H(s)=\left\{\begin{array}{l}
R_{v} \text { for series virtual resistor } \\
\frac{L_{j} s^{2}}{s+R_{v} / L_{j}} \text { for parallel resistor }
\end{array}\right.
$$

$j$ is $\mathrm{d}$ or q, depending on the equivalent circuit.

\section{F. DC-Link Model}

In a PMSG wind turbine, integrated into a grid as shown in Fig. 1, the real power flow, through the converters and the DC-link, is balanced. Neglecting losses, the net real power can be given as,

$$
P_{s}+P_{D C}+P_{g}
$$

where $P_{D C}, P_{s}$, and $P_{g}$ are the DC-link, PMSG, and power supplied to the grid respectively, given consecutively in (17), (18), and (19).

$$
\begin{gathered}
P_{D C}=v_{D C} i_{D C}=-C v_{D C} \frac{d v_{D C}}{d t} \\
P_{s}=v_{d} i_{d}+v_{q} i_{q} \\
P_{g}=v_{D g} i_{D g}+v_{Q g} i_{Q g}
\end{gathered}
$$

$v_{D C}, i_{D C}$, and $C$ refer to the voltage, current and capacitance of the DC- link capacitor respectively. $v_{D g}$ and $v_{Q g}$ are the D- and Q- axis voltages at the grid side converter terminal. Since the wind turbine and the grid are decoupled, they operate at relatively different frequencies, and the grid side axes are not necessarily the 
same as the d- and q-axes. $i_{D g}$ and $i_{Q g}$ are D- and Q- axis grid currents. Finally, the model of the DC-link can be given as,

$$
C v_{D C} \frac{d v_{D C}}{d t}=v_{D g} i_{D g}+v_{Q g} i_{Q g}+v_{d} i_{d}+v_{q} i_{q}
$$

\section{G. Grid Side Converter Controller}

In Fig. 1, the D- and Q- axis voltages at the terminal of the grid side converter are given in (21) and (22) respectively [31].

$$
\begin{gathered}
v_{D g}=v_{D s}+R_{f} i_{D g}+L_{f} \frac{d i_{D g}}{d t}-\omega_{f} L_{f} i_{Q g} \\
v_{Q g}=v_{Q s}+R_{f} i_{Q g}+L_{f} \frac{d i_{Q g}}{d t}+\omega_{f} L_{f} i_{D g}
\end{gathered}
$$

$v_{D s}$ and $v_{Q s}$ are the D- and Q- axis voltages at the terminal of the filter, where $R_{f}$ and $L_{f}$ are the filter resistance and inductance respectively, and $\omega_{f}$ is the filter frequency.

The grid side controller includes four PI controllers, as shown in Fig. 5, which control the DC- link voltage, the D- and Q- axis currents, and the reactive power [31]. All quantities with superscript * are reference inputs. Q is reactive power. $K_{p 4,} K_{p 5}, K_{p 6}, K_{p 7}, K_{i 4}, K_{i 5}, K_{i 6}$ and $K_{i 7}$ are the gains of the PI controllers. For unity power factor, the reference reactive power is maintained at zero.

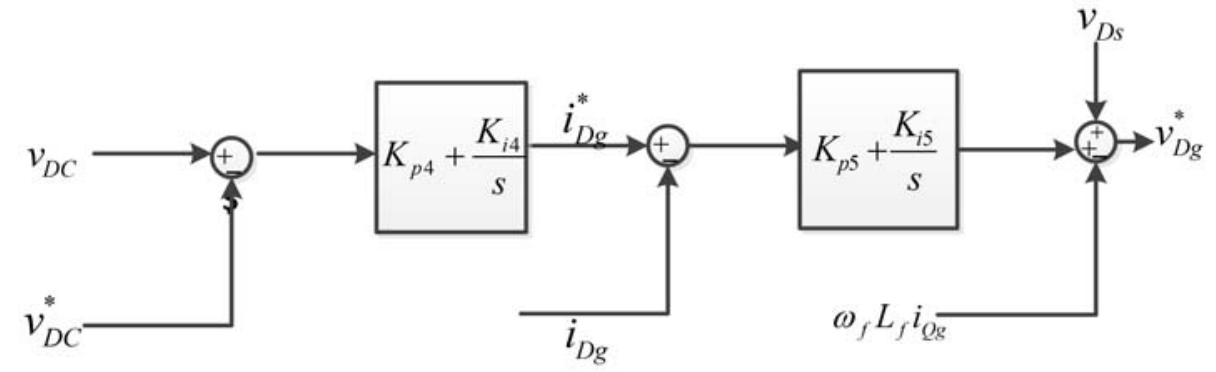

(a)

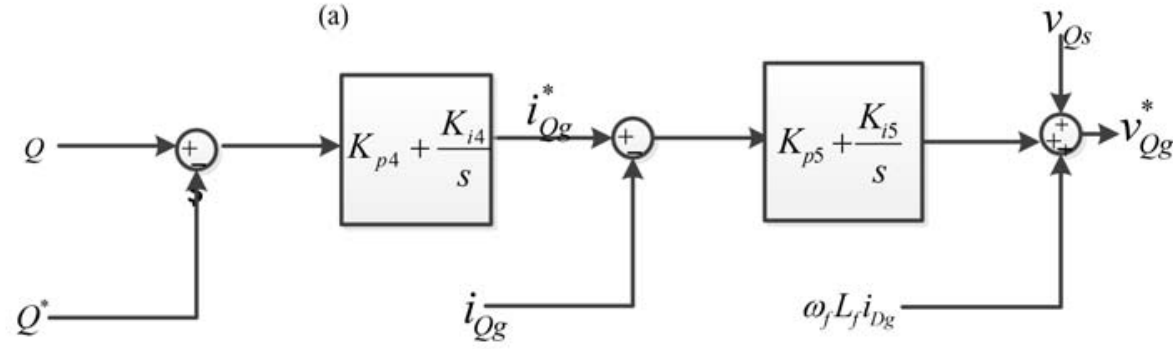

(b)

Fig. 5. Grid side control structure (a) D- axis controller (b) Q- axis controller

\section{GRID MODEL}

The PMSG wind turbine is connected to the grid through a coupling transformer and a transmission line. Fig. 6 shows the single-line diagram of the coupling transformer, the transmission line and the grid where $x_{T}$ and $x_{L}$ refer to the transformer and transmission line reactances respectively. The respective resistances are neglected. $V_{D Q i}$ is the grid voltage. The terminal voltage of the filter is considered as a reference, and $\delta$ is the angle of the grid voltage from $v_{D Q S}$.

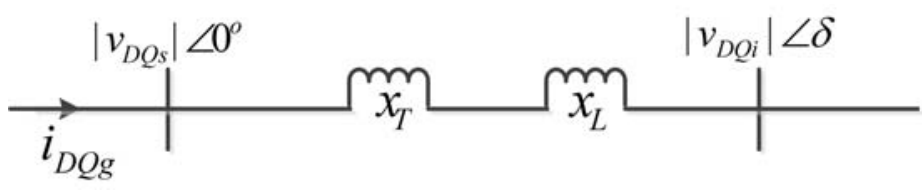

Fig. 6. One-line diagram of the grid, the transmission line and the transformer

The current, flowing from the wind turbine to the grid, can be given as, 


$$
i_{D Q g}=\frac{\left|v_{D Q s}\right| \sin 0-\left|v_{D Q i}\right| \sin \delta}{x_{T}+x_{L}}+j \frac{-\left|v_{D Q s}\right| \cos 0+\left|v_{D Q i}\right| \cos \delta}{x_{T}+x_{L}}
$$

For unity power factor, the current and the terminal voltage of the filter, $v_{D Q s}$, are in phase. Consequently, the real and imaginary parts of the current can be expressed as,

$$
\begin{gathered}
i_{D g}=\frac{-\left|v_{D Q i}\right| \sin \delta}{x_{T}+x_{L}} \\
i_{Q g}=\frac{-\left|v_{D Q s}\right|+\mid v_{D Q i} \cos \delta}{x_{T}+x_{L}}
\end{gathered}
$$

\section{SiMULATION RESULTS}

The models in Sections II and III were implemented in MATLAB $\backslash$ Simulink to verify the validity of the proposed method through time-domain simulations. The dynamic performance of a PMSG wind turbine, which is connected to a grid, depends on the system characteristics, the intermittent nature of the wind, and the load disturbances in the power system. Particularly, the nature of the wind makes the evaluation of the dynamic and small-signal performances challenging, and in this work, large and small wind speed disturbances are considered.

The performance indices used are rise time to measure speed of response, settling time to evaluate stability and speed of response, and maximum percent overshoot to assess the relative stability of the PMSG wind turbine with and without the proposed scheme. The degree of oscillation damping is also observed through damping ratio. The maximum percent overshoot and damping ratio are related as [34],

$$
M_{P}=100 e^{-\zeta \pi / \sqrt{1-\zeta^{2}}}
$$

where $M_{P}$ is the maximum percent overshoot, and $\zeta$ is the damping ratio. Sub-sections A and B present the time responses of the PMSG wind turbine, subjected to large and small disturbances in the wind speed respectively. The simulations were carried out based on the data in Tables A1 and A2.

\section{A. Large Disturbances in the Wind Speed}

In this study, a step increase of $12 \mathrm{~m} / \mathrm{s}$ in the wind speed was used, and all the higher order harmonics in (1) were neglected. Thereafter, the resulting dynamic performance of the PMSG wind turbine was observed. The following cases are considered:

Series virtual resistance: Fig. 7 shows the speed response of the PMSG wind turbine to a step wind speed when a series virtual resistance is employed in the generator side controller. As it can be observed, speed oscillations are successfully damped. Besides, the maximum percent undershoot is significantly reduced, indicating that the system has become more stable. Similarly, the rise time is reduced from 3.5 to 0.08 seconds, and the settling time is reduced from 8.0 to 6.0 seconds, as shown in Table 1. Thus, the role of the series virtual resistance in damping rotor speed oscillations is paramount for large wind speed disturbances.

The results in Figs. 8, 9, 10 and TABLE I illustrate that the oscillations in real power, reactive power, mechanical torque, electromagnetic torque, DC- link and terminal voltages are effectively suppressed. Therefore, for large disturbances, employing virtual resistors, connected in series to the stator windings, successfully improves the dynamic performance of the wind turbine.

TABLE I Dynamic performance of the PMSG wind turbine with and without series virtual resistance

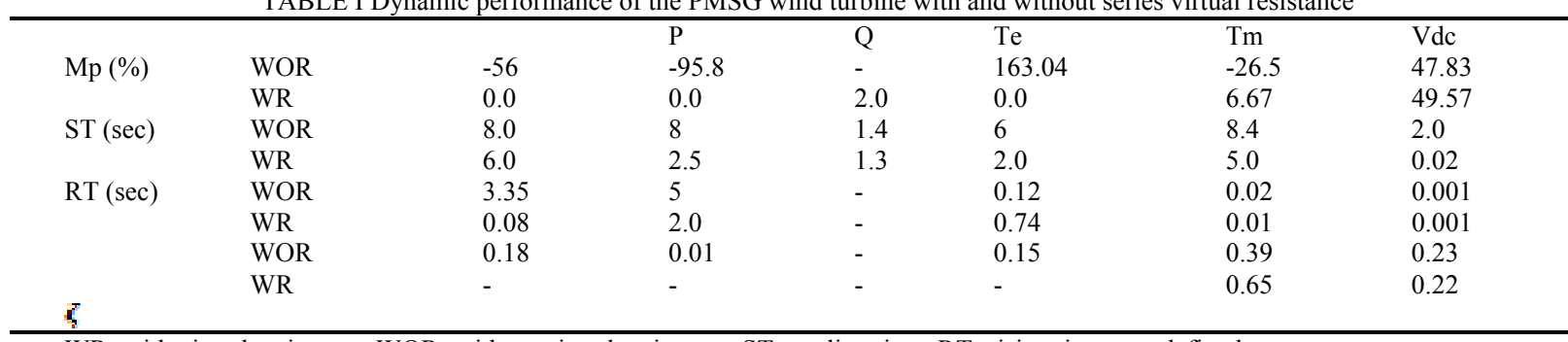

WR- with virtual resistance; WOR- without virtual resistance; ST- settling time; RT- rising time; - undefined 


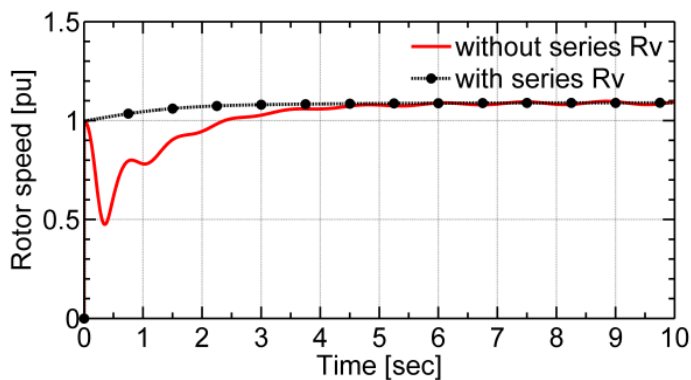

Fig. 7. Rotor speed with and without series virtual resistance
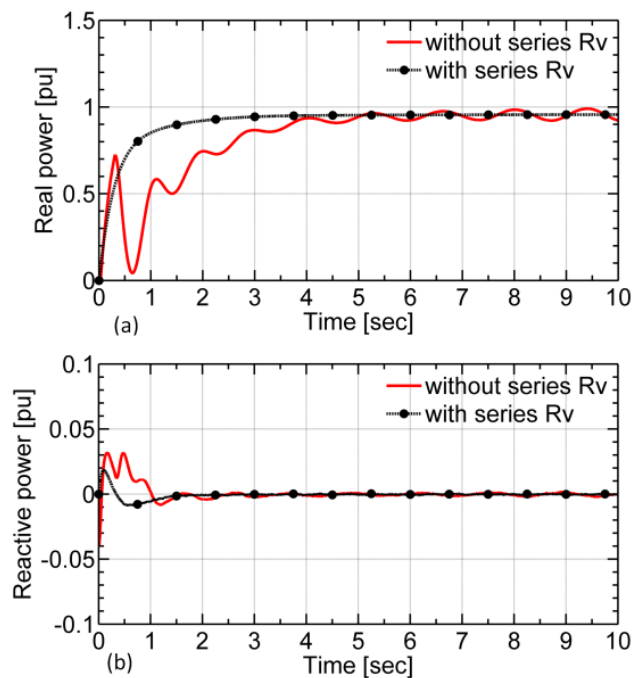

Fig. 8. Power step responses with and without series virtual resistance (a) real power (b) reactive power
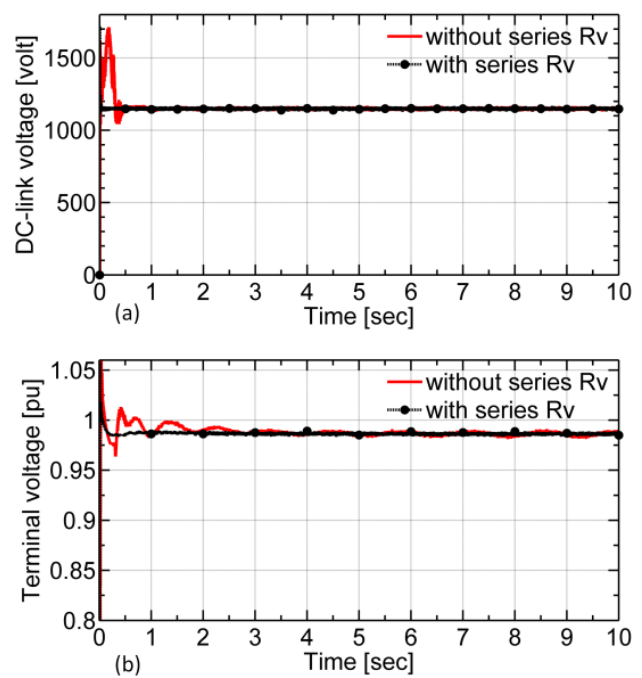

Fig. 10. Voltages with and without series virtual resistance (a) DC- link voltage (b) Terminal voltage
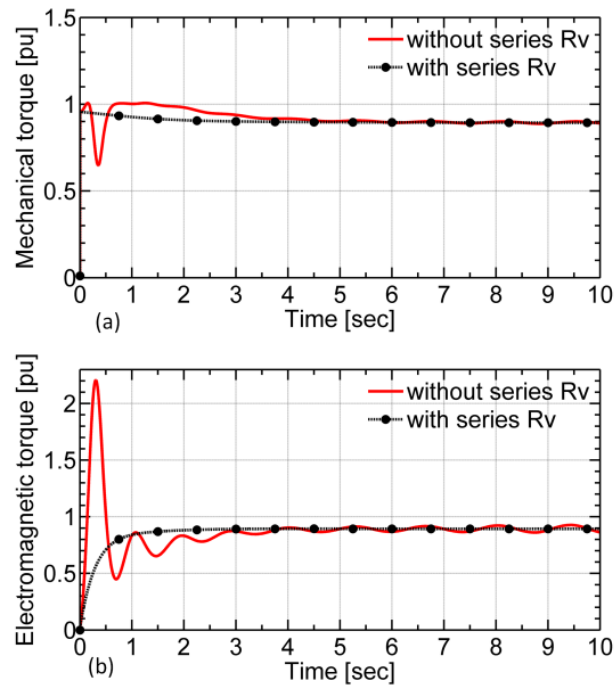

Fig. 9. Torque responses with and without series virtual resistance (a) Mechanical torque (b) Electromagnetic torque
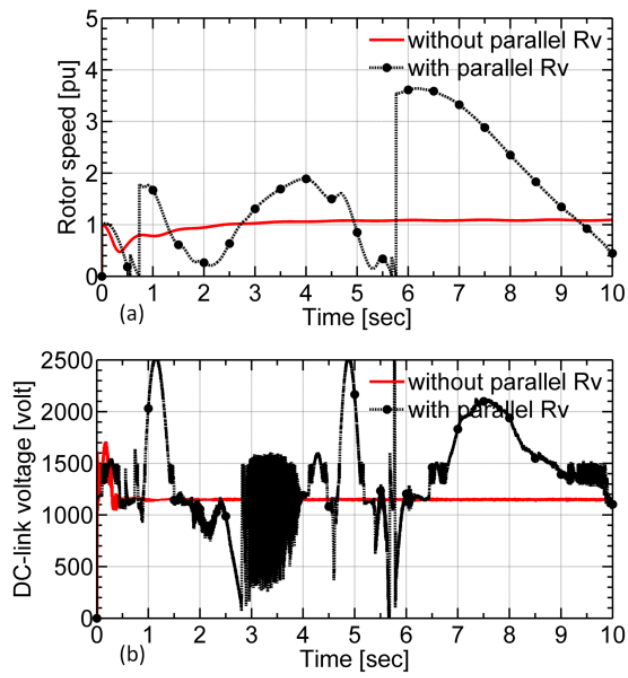

Fig. 11: Effect of parallel virtual resistance on (a) rotor speed (b) DC- link voltage

Parallel virtual resistance: In this case, after factorizing, the improper transfer function in Fig. 3 was implemented in MATLAB/Simulink as the difference of a derivative and a first-order transfer function. The virtual resistance considered remains the same as in the previous case. It is found that the effect of the parallel virtual resistance on the dynamic performance of the PMSG wind turbine is negative. The results show that the application of virtual resistors, connected to the stator windings, decreases the damping of the rotor speed oscillations. Besides, the wind turbine becomes less stable. For this particular case, the system has become unstable, as shown in Fig. 11. 


\section{B. Small Disturbances in the Wind Speed}

To study the small-signal performance of the PMSG wind turbine using time-domain simulation, harmonics and a sudden rise in the wind speed are considered, as shown in Fig. 12. At the fifth second, the wind speed suddenly rises from 10 to $12 \mathrm{~m} / \mathrm{s}$. As a parallel virtual resistance was not effective in the previous section, only a series one is considered.

The simulation result in Fig. 13 shows that rotor speed oscillations are well damped during small perturbations when a virtual resistance is employed. For the disturbance at the fifth second, the response of the wind turbine is fast and more stable with the virtual resistance.

Fig. 14 shows that the mechanical torque is nearly not affected by the virtual resistors, whereas the electromagnetic torque is effectively damped. In Fig. 14 (b), after the disturbance in the fifth second, the electromagnetic oscillation will increase if a virtual resistor is not employed.

Similarly, the increasing oscillations in real and reactive powers due to the small wind speed disturbances are suppressed by using the virtual resistors as shown in Fig. 15. The oscillations due to wind speed harmonics are also successfully damped.

In general, employing appropriate selection and connection of virtual resistors in the generator side controller significantly improves both the dynamic and small-signal performances of a PMSG wind turbine.

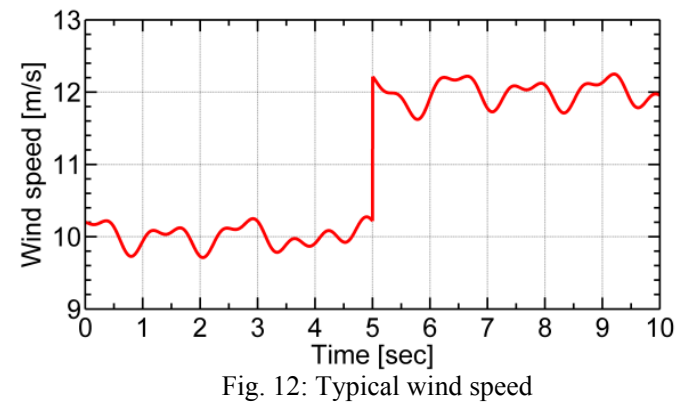

Fig. 12: Typical wind speed
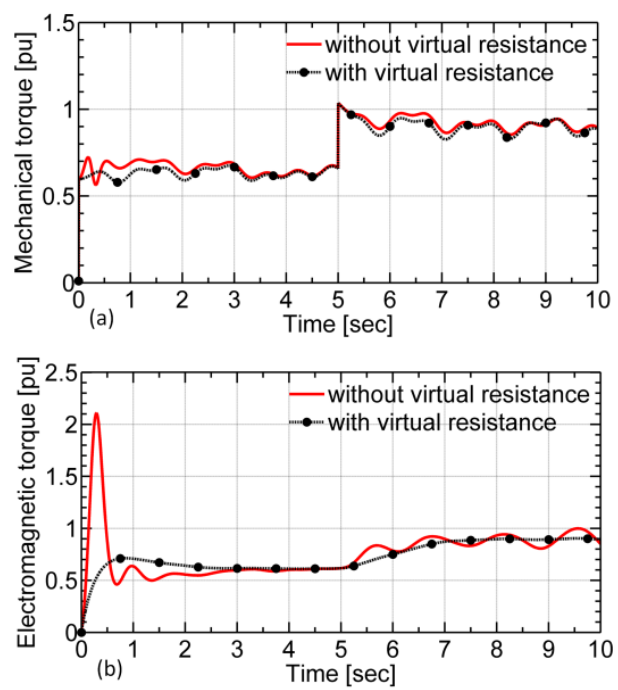

Fig. 14: Torque responses (a) mechanical (b) electromagnetic for small disturbances

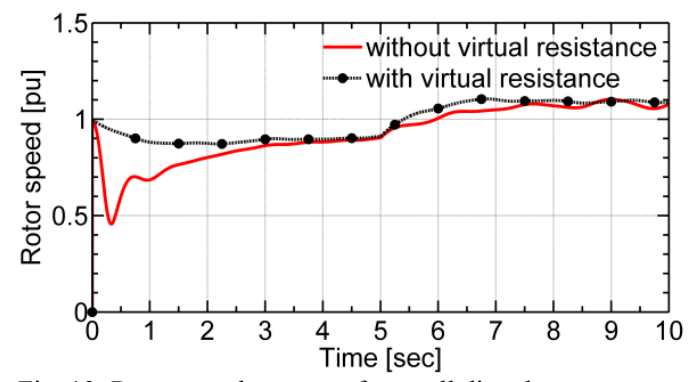

Fig. 13: Rotor speed response for small disturbances
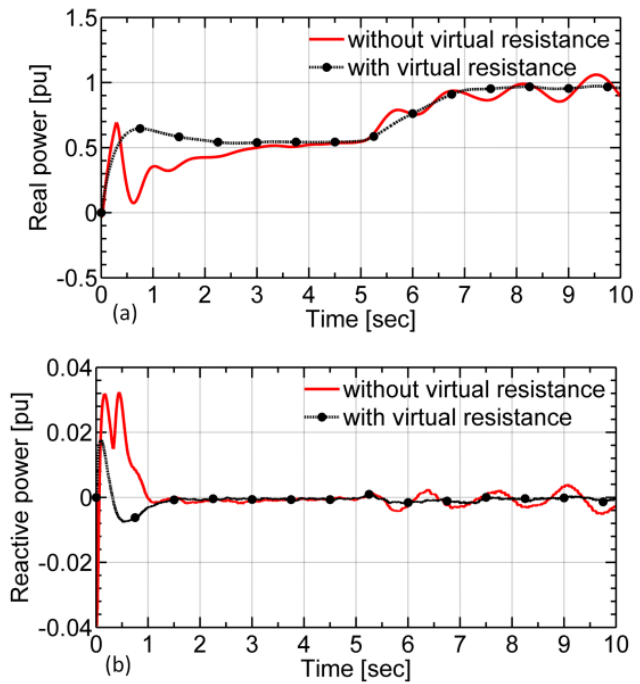

Fig. 15: (a) Real power (b) reactive power responses for small disturbances

\section{CONCLUSION}

In this paper, virtual resistors are proposed to improve the damping of local oscillations such as rotor speed, power, and torque oscillations in a PMSG wind turbine, which is connected to a power grid. The virtual resistors and the different components of the wind turbine are modeled. Virtual resistors, connected in series and parallel to the stator windings of the generator, are implemented in the generator side converter controller, and all the models have been validated in MATLAB/Simulink. Simulation results have shown that virtual resistors, connected in series to the stator windings, efficiently enhance the dynamic and small-signal performances of the wind turbine by damping local oscillations. Speed, power, and torque oscillations, caused by wind disturbances, are well damped when virtual resistors are employed. Moreover, the virtual resistors significantly improve the DC-link and the terminal voltage responses. On the other hand, virtual resistors, connected in parallel to the 
stator windings, decrease the damping performance of the wind turbine. Hence, for a better performance, the virtual resistors should be connected in series to the stator windings. Therefore, the technique proposed in this work is applicable in smoothing the rotor speed and the output power of a PMSG wind turbine. In future, the performance of a virtual RLC circuit, implemented in advanced converter controllers, on the dynamic and smallsignal performances of a PMSG wind turbine will be studied.

\section{APPENDIX}

TABLE A1 PMSG wind turbine parameters

\begin{tabular}{|c|c|c|c|}
\hline Parameter & & \multicolumn{2}{|l|}{ Value } \\
\hline Terminal voltage & & \multicolumn{2}{|l|}{$575 \mathrm{~V}$} \\
\hline$x_{T}+x_{E}$ & & \multicolumn{2}{|l|}{$0.0377 \mathrm{~m} \Omega$} \\
\hline Rated power & & \multicolumn{2}{|l|}{$1.5 \mathrm{MW}$} \\
\hline Rated frequency & & \multicolumn{2}{|l|}{$60 \mathrm{HZ}$} \\
\hline Filter resistance & & \multicolumn{2}{|l|}{$0.003 \mathrm{pu}$} \\
\hline Filter inductance & & \multicolumn{2}{|l|}{$0.3 \mathrm{pu}$} \\
\hline DC-link voltage & & \multicolumn{2}{|l|}{$1150 \mathrm{~V}$} \\
\hline Number of pole pairs & & \multicolumn{2}{|l|}{48} \\
\hline$L_{d}=L_{q}$ & & \multicolumn{2}{|l|}{$0.3 \mathrm{mH}$} \\
\hline$\phi_{p}$ & & \multicolumn{2}{|l|}{1.48 V.s. } \\
\hline Moment of inertia & & \multicolumn{2}{|l|}{$1.2 \mathrm{pu}$} \\
\hline $\boldsymbol{R}_{v}$ & & \multicolumn{2}{|l|}{$3.0 \mathrm{pu}$} \\
\hline \multicolumn{4}{|c|}{ TABLE A2 Control parameters } \\
\hline Parameter & Value & Parameter & Value \\
\hline$K_{p 1} K_{p g}$ & $0.14 \mathrm{pu}$ & $R_{p p} E_{p}$ & $0.83 \mathrm{pu}$ \\
\hline$K_{t 1}, K_{t B}$ & $2.72 \mathrm{sec}$ & $K_{i z} K_{g}$ & $5.0 \mathrm{sec}$ \\
\hline $\boldsymbol{K}_{p 2}$ & $0.84 \mathrm{pu}$ & $K_{06}$ & $1.0 \mathrm{pu}$ \\
\hline $\boldsymbol{K}_{\text {opt }}$ & $0.25 \mathrm{pu}$ & $K_{i 6}$ & $0.001 \mathrm{~s} \mathrm{ec}$ \\
\hline $\boldsymbol{K}_{\boldsymbol{P}}$ & $200 \mathrm{pu}$ & & \\
\hline $\boldsymbol{K}_{p 4}$ & $8.0 \mathrm{pu}$ & & \\
\hline $\boldsymbol{K}_{i 4}$ & $400 \mathrm{sec}$ & & \\
\hline
\end{tabular}

\section{REFERENCES}

[1] M. Asif and T. Muneer, "Energy supply, its demand and security issues for developed and emerging economies," Renewable and Sustainable Energy Reviews, vol. 11, pp. 1388-1413, Sep. 2007.

[2] REN21.2009, "Renewables global status report: 2009 Update," Paris: REN21 Secretariat, May 2009.

[3] G. Joselin Herberta, S. Iniyan, E. Sreevalsan and S. Rajapandian, "A review of wind energy technologies," Renewable and Sustainable Energy Reviews, vol. 11, pp. 1117-1145, Aug. 2007.

[4] Z. Miao, L. Fan, D. Osborn and S. Yuvarajan, "Control of DFIG-based wind generation to improve interarea oscillation damping," IEEE Transactions on Energy Conversion, vol. 24, no. 2, pp. 415-422, June 2009.

[5] A. Rolan, A. Luna, G. Vazquez, A. Daniel and G. Azevedo, "Modeling of a variable speed wind turbine with a permanent magnet synchronous generator," in IEEE International Symposium on Industrial Electronics, Seoul, pp. 734 - 739, July 2009.

[6] L. B. Shi, L. Kang, L. Z. Yao, S. Y. Qin, R. M. Wang and J. P. Zhang, "Effects of wind generation uncertainty and volatility on power system small-signals Stability," Journal of Electrical Engineering Technology, vol. 9, no. 1, pp. 60-70, Jan. 2014.

[7] H. Espen, I. Norheim and K. Uhlen, "Large-scale wind power integration in Norway and impact on damping in the Nordic grid," Wind Energy, vol. 8, no. 3, pp. 375-384, Jul. 2005.

[8] M. A. Mahmud, M. J. Hossain, H. R. Pota and C. Zhang, "Investigation of critical factors affecting dynamic stability of wind generation systems with permanent magnet synchronous generators," in proc. the International Federation of Automatic Control, Cape Town, South Africa, pp. 7665 - 7670, August 2014.

[9] E. Mahersi, A. Khedher and M. Mimouni, "The wind energy conversion system using PMSG controlled by vector control and SMC strategies," International Journal of Renewable Energy Research, vol. 3, no. 1, pp. 41-50, 2013.

[10] K. Zhao, G. Li, B. Wang and M. Zhou, "Grid-connected topology of PMSG wind power system based on VSC-HVDC," in Electric Utility Deregulation and Restructuring and Power Technologies (DRPT), Weihai, Shandong, pp. 297 - 302, July 201. 
[11] N. Abdolghani, J. Milimonfared and G. B. Gharehpetian, "A direct torque control method for CSC based PMSG wind energy conversion systems," in International Conference on Renewable Energies and Power Quality, Santiago de Compostela, Spain, pp. 1- 7 , March 2012.

[12] WWEA, "World wind energy report 2010", Cairo, Oct - Nov 2011.

[13] H. Ahmadi and H. Ghasemi, "Maximum penetration level of wind generation considering power system security limits," IET Generation, Transmission \& Distribution, vol. 6, no. 11, pp. 1164-1170, Nov. 2012.

[14] J. L. Domı'nguez-Garci'a, O. G. Bellmunt, F. D. Bianchi and A. Sumper, "Power oscillation damping supported by wind power: a review," Renewable and Sustainable Energy Reviews, vol. 16, pp. 4994-5006, Sep. 2012.

[15] A. Sanchez, M. Molina and A. Lede, "Dynamic model of wind energy conversion systems with PMSG-based variable-speed wind turbines for power system studies," International Journal of Hydrogen Energy, vol. 37, pp. 10064-10069, July 2012.

[16] A. Westlake, J. Bumby and E. Spooner, "Damping the power-angle oscillations of a permanent-magnet synchronous generator with particular reference to wind turbine applications," IEE Proceedings Electric Power Applications, vol. 143, no. 3, pp. 269 - 280, May 1996.

[17] C. Jauch, S. M. Islam, P. Sørensen and B. B. Jensen, "Design of a wind turbine pitch angle controller for power system stabilisation," Renewable Energy, vol. 32, p. 2334-2349, Nov. 2007.

[18] C. Jauch, T. Cronin, P. Sørensen and B. Jensen, "A fuzzy logic pitch angle controller for power system stabilization," Wind Energy, vol. 10, pp. 19-30, July 2007.

[19] H. Geng, D. Xu, B. Wu and G. Yang, "Active damping for PMSG-based WECS with DC-Link current estimation," IEEE Transactions on Industrial Electronics, vol. 58, no. 4, pp. 1110-1119, Feb. 2011.

[20] Xu, H. Geng and Dewei, "Stability analysis and improvements for variable-speed multipole PMSG-based wind energy conversion system," IEEE Transactions on Sustainable Energy, vol. 2, no. 4, pp. 459-466, Oct. 2011.

[21] B. Han, Y. Wang, H. Li and X. Zhang, "Supplementary power control of PMSG-based wind farms for system dynamic stability," in IEEE international conference on electrical machines and systems, Busan, pp. 291 - 295, October 2013.

[22] S. Rodrigues, R. T. Pinto, P. Bauer and J. Pierik, "Multi-objective optimization of a PMSG control system through small-signal analysis," in IEEE ECCE Asia Downunder (ECCE Asia), Melbourne, pp. 1189 - 1195, June 2013.

[23] A. Adamczyk, R. Teodorescu and P. Rodriguez, "Control of full-scale converter based wind power plants for damping of low frequency system oscillations," in IEEE PowerTech, Trondheim, pp. 1-7, June 2011.

[24] X. Zhang, Y. Wang and H. Li, "Control of PMSG-based wind turbines to damp the power system oscillations," in IEEE PEDS, Beijing, pp. $1-4$, Sept. 2011.

[25] L. Fan, H. Yin and Z. Miao, "Active/reactive power modulation of DFIG-based wind generation for inter area oscillation damping," IEEE Transactions on Energy Conversion, vol. 26, no. 2, pp. 513-521, Dec. 2011.

[26] T. Ackermann, Wind power in power systems, John Wiley and Sons, Stockholm, Sweden, pp. $563-565,2005$.

[27] J. F. McGowan and G. J. Manwell, Wind energy explained: design and application, John Wiley \& Sons, Washington DC, 2009.

[28] I. Al-Bahadly, Wind turbines, InTech, Rijek, Croatia, 2011.

[29] B. Fox, D. Flynn, L. Bryans, N. Jenkins, D. Milborrow, M. O’Malley, R. Watson and O. Anaya-Lara, Wind power integration connection and system operational aspects, The Institution of Engineering and Technology, London, United Kingdom, 2007.

[30] F. Wu, X.-P. Zhang and a. P. Ju, "Small signal stability analysis and control of the wind turbine with the direct-drive permanent magnet generator integrated to the grid," Electric Power Systems Research, vol. 79, pp. 1661-1667, Dec. 2009.

[31] S. K. Yun, Y. C. Il and I. M. Seung, "Tuning of the PI controller parameters of a PMSG wind turbine to improve control performance under various wind speeds," Energies, vol. 8, pp. 1406-1425, Feb. 2015.

[32] W. Gullvik, L. Norum and R. Nilsen, "Active damping of resonance oscillations in LCL-filters based on virtual flux and virtual resistor," in European Conference on Power Electronics and Applications, Aalborg, pp. 1 - 10, Sept. 2007.

[33] P. Dahono, "A method to damp oscillations on the input LC filter of current-type AC-DC PWM converters by using a virtual resistor," in The 25th International Telecommunications Energy Conference, Yokohama, Japan, pp. 751 - 761, Oct. 2003.

[34] K. Ogata, Modern Control Engineering, Prentice Hall, New Jersy, pp. 219 - 336, 2002

\section{Authors}

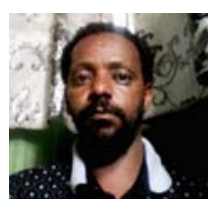

Ayele Nigussie Legesse was born in Ethiopia in 1982. He received the B.Sc. degree from Bahir Dar University and M.Sc. from Addis Ababa University, Ethiopia in 2004 and 2010. Currently, he is pursuing $\mathrm{PhD}$ at the University of KwaZulu-Natal, South Africa. His areas of interest are power system control, stability and dynamics. E-mail: 21584668@stu.ukzn.ac.za

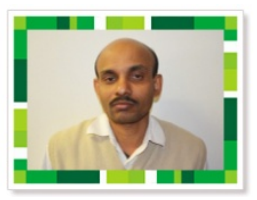

Akshay Kumar Saha received the $\mathrm{PhD}$ degree in electrical engineering from Jadavpur University, Kolkata, India, in 2009. He is currently a Senior Lecturer in electrical engineering with the University of KwaZulu-Natal, Durban, South Africa. Dr. Saha is a registered Professional Engineer with the Engineering Council of South Africa and a senior member of the South African Institute of Electrical Engineering. E-mail: saha@ukzn.ac.za

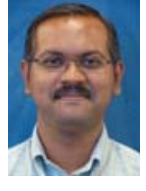

Rudiren Pillay Carpanen (S-99, M-07, SM-14) was born in Rose Hill, Mauritius. He received the BEng (Hons) degree from the University of Mauritius in 2002, and the MScEng degree and PhD degree from the University of KwaZulu-Natal, South Africa in 2005 and 2013. He is currently a Lecturer at the University of KwaZulu-Natal. His research interests include power system dynamics, FACTS, and sub synchronous resonance. E-mail: PillayR21@ukzn.ac.za 